\title{
Is a High Homocysteine Level Related to Thrombosis?
}

\section{Yüksek Homosistein Seviyesi Trombozla İlgili mi?}

\section{Şinasi Özsoylu}

Retired Prof of Pediatrics, Hematology, Hepatology, Ankara, Turkey

Honorary fellow of American Academy of Pediatrics

Honorary member of American Pediatric Society

\section{To the Editor,}

The study by Eğin and Akar [1] entitled, First observation of MTHFR 678C-A (Ala 222 Ala) single nucleotide polymorphism, in the recent issue of the Journal (2012; 29: 204-5) requires questioning its importance to thrombosis in the light of Dayal et al.'s findings in a mouse model [2]. I used to think that high homocysteine level important in thrombosis, whereas currently I question such knowledge. As such, I think the authors must show the functional effect of their observation in blood coagulation and its relationship to the thermolabile variant of MTHFR ?

\section{References}

1. Eğin Y, Akar N. First Observation of MTH FR 678 C-A (Ala222Ala) Single Nucleotide Polymorphism. Turk J Hematol 2012; 29:204-205

2. Dayal S, Chauhan AK, Jensen M, Leo L, Lynch CM, Faraci FM, Kruger WD, Lentz SR. Paradoxical absence of a prothrombotic phenotype in a Mouse model of severe hyperhomocysteinemia. Blood 2012;119:3176-3183. 